V. 14 N. 1

JAN-ABR 2018

ISSN 2317-6172

- FGV DIREITO SP

Recibido: 20.12.2016

Aprobado: 27.11.2017

DOI: http://dx.doi.org/10.1590/2317-6172201808

1 Universidad Nacional del Centro de la Provincia de Buenos Aires Buenos Aires - Argentina https://orcid.org/0000-0003-2400-8173

\section{El derecho al nombre en relación con la identidad de género dentro del Sistema Interamericano de Derechos Humanos: el caso del Estado de Costa Rica}

THE RIGHT TO A NAME IN RELATION TO GENDER IDENTITY WITHIN THE INTER-AMERICAN HUMAN RIGHTS SYSTEM: THE CASE OF THE STATE OF COSTA RICA

\author{
Eduardo J. Arrubia
}

\section{Resumen}

Desde el plano de la realidad social, uno de los aspectos principales que caracteriza al derecho a la identidad de género es el ejercicio del derecho al nombre. El Estado de Costa Rica ha solicitado a principios de 2016 a la Corte Interamericana de Derechos Humanos que emita una opinión consultiva acerca de la compatibilidad de su ordenamiento jurídico interno que impone un trámite judicial para que las personas puedan modificar su nombre de pila, en relación con el Derecho Internacional de los Derechos Humanos. Por consiguiente, se formula un análisis evolutivo de esta rama jurídica a través de la propia jurisprudencia del tribunal en cuestión. Se expone que las categorías de orientación sexual y de identidad de género gozan de status convencional a los efectos de aplicar los principios pro persona y de no discriminación. En consecuencia, se concluye que la aplicación de la legislación civil interna de Costa Rica es contraria al Derecho Internacional de los Derechos Humanos siempre que se trate del ejercicio del cambio de nombre como corolario de asumir una identidad de género contraria a la determinada por el sexo biológico.

\section{Palabras clave}

Identidad de género; nombre; Derechos Humanos; sexualidad; no discriminación.

\begin{abstract}
From a social viewpoint, one of the main features that ensures the right to gender identity is the exercise of the right to a name. In early 2016, Costa Rica consulted the Inter-American Human Rights Court about the compatibility between International Human Rights Law and its domestic juridical system, which requires a judicial procedure in order to have a person's first name legally modified. Therefore, we suggest a progressive analysis of this legal branch throughout the jurisprudence ruled by the referred Court. We also claim that the concepts of sexual orientation and gender identity both bear conventional status so as to make the non-discrimination and pro persona principles effective. We conclude that in this matter the enforcement of Costa Rica's civil domestic law is not consistent with the International Human Rights Law.
\end{abstract}

\section{Keywords}

Gender identity; Human Rights; name; sexuality; non-discrimination. 


\section{INTROITO}

El 18 de mayo de 2016 el Estado de Costa Rica presentó en la Secretaría de la Corte Interamericana de Derechos Humanos (Corte IDH) una solicitud de opinión consultiva a fin de que elTribunal interpretara las obligaciones sobre: a) "la protección que brindan los artículos 11.2, 18 y 24 en relación con el artículo 1 de la CADH al reconocimiento del cambio de nombre de las personas, de acuerdo con la identidad de género de cada una"; b) "la compatibilidad de la práctica que consiste en aplicar el artículo 54 del Código Civil de la República de Costa Rica, Ley n. 63 del 28 de setiembre de 1887, a las personas que deseen optar por un cambio de nombre a partir de su identidad de género, con los artículos 11.2, 18 y 24, en relación con el artículo 1 de la Convención"; y c) "la protección que brindan los artículos 11.2 y 24 en relación con el artículo 1 de la CADH al reconocimiento de los derechos patrimoniales derivados de un vínculo entre personas del mismo sexo" (Corte IDH, 2017, p. 3-4). De esta manera, el derecho a readecuar el nombre de pila se presenta como una necesidad que proviene del hecho de asumir un género distinto del sexo biológicamente asignado al nacer. Es decir, este derecho aparece como una cuestión vinculada a las personas transexuales y transgénero.

En esta línea, si bien la identidad de género y la orientación sexual constituyen categorías fuertemente vinculadas y la petición de Costa Rica se refiere a ambas, este artículo tiene como finalidad explorar solamente las diversas connotaciones que constituyen la materialidad del ejercicio del derecho humano a la identidad de género. Entre éstas, el derecho al nombre emerge como una pieza central, todo lo cual será abordado desde el enfoque del Derecho Internacional de los Derechos Humanos. Para ello se hará hincapié en el Sistema Interamericano en el cual se inserta la solicitud de opinión consultiva antes mencionada.

De manera preliminar, es importante destacar que la Comisión Interamericana de Derechos Humanos (CIDH) ha definido a la orientación sexual como "la capacidad de cada persona de sentir una profunda atracción emocional, afectiva y sexual por personas de un género diferente al suyo, o de su mismo género, o de más de un género, así como a la capacidad mantener relaciones íntimas y sexuales con estas personas" (COMISIÓN INTERAMERICANA DE DERECHOS HUMANOS, 2012, p. 6). Mientras que por el contrario la identidad de género ha sido conceptualizada como:

...la vivencia interna e individual del género tal como cada persona la siente profundamente, la cual podría corresponder o no con el sexo asignado al momento del nacimiento, incluyendo la vivencia personal del cuerpo (que podría involucrar la modificación de la apariencia o la función corporal a través de medios médicos, quirúrgicos o de otra índole, siempre que la misma sea libremente escogida) y otras expresiones de género, incluyendo la vestimenta, el modo de hablar y los modales. (COMISIÓN INTERAMERICANA DE DERECHOS HUMANOS, 2012, p. 7) 
El nudo problemático está centrado en la necesidad de especificar si se puede afirmar, por un lado, que exista un derecho a la identidad de género reconocido en los textos convencionales de Derechos Humanos y, por el otro, en caso de ser afirmativa esta respuesta, si el Estado de Costa Rica estaría transgrediendo dichas convenciones a través de la aplicación del artículo 54 de su Código Civil en casos de peticiones de cambio de nombre fundadas en el ejercicio de aquel derecho a la identidad de género. Para esto es necesario precisar que dicha norma de derecho doméstico establece que "Todo costarricense inscrito en el Registro del Estado Civil puede cambiar su nombre con autorización del Tribunal lo cual se hará por los trámites de la jurisdicción voluntaria promovidos al efecto" (COSTA RICA, 1887). En este sentido, este artículo se propone contribuir a la literatura existente a través del análisis de la situación fáctica y normativa del Estado de Costa Rica a partir de los estándares internacionales en materia de diversidad sexual y derechos humanos.

En cuanto a la metodología a seguir, en primer lugar se hará referencia a los despliegues actuales de la idea de sexualidad humana en un marco de diversidad, para lo cual se explorará literatura pertinente a la materia a los efectos de establecer la construcción social del género y su canalización en términos de Derechos Humanos. En segundo término, se dará cuenta de la recepción del derecho a la identidad de género en el plano convencional internacional a través de una mirada evolutiva e interpretación pro persona que emerge de la propia jurisprudencia de la Corte Interamericana de Derechos Humanos. Este tipo de interpretación implica que, ante casos de dudas, la tarea interpretativa efectuada sobre las normas siempre deberá favorecer y garantizar la dignidad de la persona humana. En tercer orden, se abordarán las cláusulas de igualdad reguladas por la Convención Americana de Derechos Humanos, lo cual permitirá exponer la articulación del principio de no discriminación en relación a la categoría de identidad de género. Por último, se señalará y fundamentará que la legislación interna del Estado de Costa Rica vinculada al cambio de nombre resulta lesiva de este derecho al supeditar dicha modificación al contralor judicial. Para ello, se hará referencia a los avances normativos que se han producido con la finalidad de proteger el derecho a la identidad de género en Costa Rica, se tendrá en cuenta también jurisprudencia en la que se ha reflejado esta discusión y la legislación argentina como parámetro de protección adecuada de este derecho.

\section{Sexualidades, Género y Derechos Humanos}

La sexualidad humana siempre ha sido objeto de análisis de diversas disciplinas. Desde la medicina, hasta las ciencias más blandas como la psicología, la sociología o la antropología, entre otras, se han preguntado por el fenómeno de la sexualidad que con el devenir de los tiempos se cristalizó en la diversidad sexual, o en las sexualidades en plural. La heterogeneidad de las pasiones, las emociones y los sentimientos de las personas pusieron en evidencia que la orientación sexual y la identidad de género no son más que otros aspectos de la vasta 
complejidad del ser. Sin embargo, la pertenencia del individuo a una estructura social es lo que condiciona prima facie las manifestaciones sexuales de los sujetos. De esta manera, como sostiene Duque Yepes (2006, p. 17), la socialización puede ser descripta desde dos ángulos, uno objetivo, a partir del influjo que la sociedad ejerce en el individuo y otro subjetivo, a partir de la respuesta o reacción del individuo a la sociedad. A través de estas interacciones entre el individuo y el tejido social, se van construyendo realidades estereotipadas. Esto genera que en muchas ocasiones las vivencias y experiencias más difusas coloquen a las personas por fuera de esos moldes heteronormativos provocando entonces la aparición del estigma. En este sentido, Goffman sostiene que:

...un individuo que podía haber sido fácilmente aceptado en un intercambio social corriente posee un rasgo que puede imponerse por la fuerza a nuestra atención y que nos lleva a alejarnos de él cuando lo encontramos, anulando el llamado que nos hacen sus restantes atributos... construimos una teoría del estigma, una ideología, para explicar su inferioridad y dar cuenta del peligro que representa esa persona. (GOFFMAN, 2012, p. 17)

Estas consideraciones en relación al estigma influyen directamente a la hora de determinar el contenido de los Derechos Humanos. Por ejemplo, la Corte IDH (2016, párr. 120) en un caso reciente, denominado "Flor Freire vs. Ecuador" sostuvo claramente que la categoría de orientación sexual como derecho exigible no solo se refiere a que la persona sea homosexual realmente o manifieste serlo, sino que también abarca el hecho de que los demás la perciban como tal independientemente de que lo sea de manera real, a los efectos de establecer la medida de un acto discriminatorio. Es decir, cuando se discrimina a un sujeto por su orientación sexual, no es relevante si el individuo discriminado es homosexual, sino que lo que importa es que sus rasgos estereotipados hayan sido individualizados por el agente discriminador a los efectos de producir la exclusión o el menoscabo de sus derechos. Entonces, es producto del estigma construido socialmente que la corte acuñó la distinción mencionada entre orientación sexual real y orientación sexual percibida.

Por consiguiente, a raíz de la mirada ajena que convierte al ser humano en objeto de evaluación permanente, y más aún en materia de sexualidad en la que ésta nos define frente a los otros a través de las distintas conductas que vayamos asumiendo, se construye la idea de la identidad sexual. Ésta tiene dos vertientes. Una estática, que está conformada por sus elementos inmutables, por sus caracteres anatómicos y su morfología exterior; y otra dinámica, que se centra en el aspecto psico-social que puede cambiar, en mayor o menor medida, a través del tiempo y se expresa y exterioriza en la personalidad del sujeto, en su actitud habitual, en su comportamiento, sus gestos, su manera de ser (FERNANDEZ SESSAREGO, 1992, p. 113). En este orden de ideas, la identidad aparece fuertemente ligada a la noción de libertad, en sus sentidos tanto positivo como negativo (BERLIN, 2002, p. 168). Así, la persona 
debe poder desarrollar su vivencia de género a través de su comportamiento, su vestimenta, sus modales y al mismo tiempo no tropezar con límites por parte del Estado ni de los particulares en cuanto a la autorrealización de su propia personalidad sin resultar perjudicial para los demás. Esta vinculación con la libertad, dentro del Derecho Internacional en el ámbito del denominado soft law, la encontramos precisada en relación al reconocimiento de la personalidad jurídica de personas LGTBI en los "Principios sobre la aplicación de la legislación internacional de derechos humanos en relación con la orientación sexual y la identidad de género" también conocidos como Principios de Yogyakarta. En consecuencia, en el texto correspondiente al tercer principio se menciona que "la orientación sexual o identidad de género que cada persona defina para sí, es esencial para su personalidad y constituye uno de los aspectos fundamentales de su autodeterminación, su dignidad y su libertad" y que "ninguna persona será sometida a presiones para ocultar, suprimir o negar su orientación sexual o identidad de género" (COMISIÓN INTERNACIONAL DE JURISTAS, 2007, p. 12).

Desde una perspectiva histórica, los aportes del feminismo al introducir la categoría género al marco conceptual de sus estudios tuvieron una gran relevancia en el sentido de que se comenzó a analizar al sexo no solo como algo definido biológicamente, sino que el acento se trasladó hacia un enfoque cultural de construcción de roles socialmente esperados por encima de la genitalidad de nacimiento desde una mirada crítica (LAMAS, 2002, p. 37). Precisamente, en esta dicotomía entre naturaleza y cultura se inscriben los cuerpos y las vivencias de las personas que no siempre se adecuan a los mandatos culturales heteronormativos. Así, la CIDH ha reconocido que son nuestras creencias acerca del género, y no la ciencia, las que definen el sexo (COMISIÓN INTERAMERICANA DE DERECHOS HUMANOS, 2015, p. 30). En este contexto, deviene imperioso legitimar, a través del Derecho Internacional, la autodeterminación a la hora de definir la propia identidad, corporalidad y sexualidad del ser humano en su calidad de persona digna. Dignidad que no es dada naturalmente, sino que debe ser construida en aras de proteger los derechos más fundamentales de la persona humana. Pero como sostiene Nino "además de ese imprescindible e imperioso reconocimiento, debe apuntarse a un plano todavía más profundo: la formación de una consciencia moral de la humanidad acerca del valor de estos derechos y de la aberración inherente a toda acción dirigida a desconocerlos" (NINO, 2007, p. 4).

Esta legitimación a la que se hace referencia proviene del entendimiento de que aunque el papel normativo sea central en el campo de la juridicidad, lo cierto es que el derecho, y en el caso objeto de este trabajo, el Derecho Internacional de los Derechos Humanos, emite prescripciones y lo hace legitimando, reconociendo, otorgándole la palabra a unos y negándosela a otros (RUIZ, 2003, p. 52). De esta manera, la pregunta medular que emerge está vinculada con determinar en qué medida la identidad de género ha sido receptada como un derecho humano en el ámbito del Derecho Internacional de los Derechos Humanos y de qué manera el derecho al nombre se inscribe en el contexto del pleno ejercicio de este derecho a la identidad de género. 


\section{LA IDENTIDAd De GÉNero COMO DERECHO TUTElado POR El DeRECHO}

INTERNACIONAL DE los Derechos Humanos: LA INTERPRETACIÓN PRO PERSONA Es sabido ya que la igualdad y la no discriminación son reglas reconocidas por el Derecho Internacional que obligan a todos los Estados. Desde el Sistema Universal de protección de Derechos Humanos, su aplicación viene consagrada a raíz de la Carta de Naciones Unidas (artículos 1 y 55) y de la Declaración Universal de Derechos Humanos (artículo 2) (PRIETO SANCHIS, 1996, p. 81). Por consiguiente, entre las discriminaciones que se prohíben universalmente se encuentra aquella que es realizada contra una persona o grupo de personas por el mero hecho de pertenecer a una minoría (PRIETO SANCHIS, 1996, p. 81).

En el marco del principio de igualdad, tanto la identidad de género como la orientación sexual constituyen criterios prohibidos de discriminación (conocidos también bajo el rótulo de "categorías sospechosas"), junto con otros tales como la raza, la religión, la nacionalidad, etc. Y, por consiguiente, guardan entre sí ciertas características comunes que le dan sentido a su existencia jurídica, a saber, (1) tienen que ver con un aspecto central de la identidad de la persona y no meramente tangencial; (2) están asociadas con prácticas históricas de discriminación y subordinación; (3) identifican a grupos con escaso poder político dentro de la sociedad, o sea, para hacerse valer en los órganos de representación; y (4) no corresponden con un criterio racional para distribuir cargas y beneficios en una sociedad (UPRIMNY; SANCHEZ, 2014, p. 601).

Existen dos normas expresas en materia de discriminación en la Convención Americana sobre Derechos Humanos (CADH). Una de ellas es la del artículo 1.1 que establece que:

Los Estados Partes en esta Convención se comprometen a respetar los derechos y libertades reconocidos en ella y a garantizar su libre y pleno ejercicio a toda persona que esté sujeta a su jurisdicción, sin discriminación alguna por motivos de raza, color, sexo, idioma, religión, opiniones políticas o de cualquier otra índole, origen nacional o social, posición económica, nacimiento o cualquier otra condición social. (COMISIÓN INTERAMERICANA DE DERECHOS HUMANOS, 1969)

Y la otra, el artículo 24 en relación a la igualdad ante la ley especifica que "Todas las personas son iguales ante la ley. En consecuencia, tienen derecho, sin discriminación, a igual protección de la ley" (COMISIÓN INTERAMERICANA DE DERECHOS HUMANOS, 1969).

En consideración de que los tratados y convenciones internacionales de Derechos Humanos son normas jurídicas impregnadas de las características coyunturales de su propio surgimiento, va de suyo que la interpretación que se haga de estos textos debe ser dinámica, atendiendo a las circunstancias cambiantes que evidencia la evolución de las sociedades a través del tiempo (Corte IDH, 2012, párr. 83). En consecuencia, la Corte IDH ha sostenido que a la hora de interpretar el sentido de la expresión “otra condición social” propia del artículo 1.1 de la CADH antes referido corresponde escoger la alternativa hermenéutica más favorable a 
la tutela de los derechos de la persona humana, conforme a la aplicación del principio pro persona (Corte IDH, 2012, párr. 84). Esto adquiere mayor relevancia si subsumimos las opiniones de la Corte IDH en la expresión "toda forma pertinente de derecho internacional aplicable en las relaciones entre las partes" que corresponde al artículo 31.3.C de la Convención de Viena sobre el Derecho de los Tratados que habilita a interpretar los textos convencionales con otros elementos que no sean únicamente aquellos que emergen de la literalidad misma de sus términos.

Además, la Corte IDH (2004, párrs. 172 y 173) dejó asentada jurisprudencialmente la aplicación del principio pro persona en relación a la tarea de interpretación de las convenciones de Derechos Humanos al sostener en el caso "19 comerciantes contra Colombia" que:

172. El artículo 31.1 de la Convención deViena sobre el Derecho de losTratados de 1969 indica que [...] un tratado deberá interpretarse de buena fe conforme al sentido corriente que haya de atribuirse a los términos del tratado en el contexto de éstos y teniendo en cuenta su objeto y fin.

173. En el presente caso el derecho a un debido proceso debe ser analizado de acuerdo al objeto y fin de la Convención Americana, cual es la eficaz protección de la persona humana, es decir, debe hacerse una interpretación pro persona. (REY CANTOR, 2007, p. 97)

En materia de derechos humanos vinculados a la diversidad sexual esta evolución puede advertirse en el relevamiento realizado por la Comisión Internacional de Juristas (2009, p. 31) según el cual se sostiene que:

...la Asamblea General de la ONU ha instado a todos los Estados a garantizar la protección efectiva del derecho a la vida y a investigar con prontitud y exhaustivamente todos los asesinatos que se cometan por cualquier razón discriminatoria, incluida la orientación sexual. La Asamblea Parlamentaria del Consejo de Europa ha adoptado varias resoluciones relativas a la cuestión de la discriminación por razones de orientación sexual e identidad de género. Recientemente, la Asamblea General de la Organización de Estados Americanos adoptó su primera resolución en materia de derechos humanos, orientación sexual e identidad de género. Adicionalmente, nuevos instrumentos internacionales han integrado explícitamente la orientación sexual y la identidad de género en la lista de razones prohibidas de discriminación.

De esta manera, los Principios de Yogyakarta sobre la aplicación de la legislación internacional de Derechos Humanos en relación con la orientación sexual y la identidad de género constituyen una norma de soft law ilustrativa del referido proceso evolutivo a la hora de interpretar las convenciones internacionales y también representan una pauta de orientación 
hermenéutica a los fines de incorporar el enfoque de identidad de género y orientación sexual para una lectura eficaz de los instrumentos internacionales de Derechos Humanos. Máxime, cuando la propia Corte IDH (2012, párr. 91) ha reconocido en su jurisprudencia que estos derechos están amparados por el artículo 1.1 de la CADH. Para esto se ha hecho expresa referencia a las resoluciones que la Asamblea General de la Organización de los Estados Americanos ha adoptado, como así también a la jurisprudencia del Tribunal Europeo de Derechos Humanos que en el mismo sentido ha incluido a la orientación sexual en el marco normativo del artículo 14 del Convenio Europeo de Derechos Humanos, todo lo cual lleva a pensar en un carácter más duro que flexible de estos "Principios" a pesar de no contar con rango convencional.

Además, cuando se trata de Derechos Humanos, se debe formular la necesaria articulación entre las normas del Sistema Universal con aquellas de los sistemas regionales. Así, por ejemplo, el caso contencioso "Niños de la calle (Villagrán Morales y otros) vs. Guatemala" constituyó la primera vez en que la Corte IDH reconoció a través de la aplicación de una regla de Derecho Internacional, que estaba habilitada a utilizar tratados del sistema universal al interpretar una norma del sistema regional (BELOFF, 2016, p. 23). Esto permite incorporar al análisis la norma del artículo 26 del Pacto Internacional de Derechos Civiles y Políticos (PIDCP), cuyo texto análogo al del artículo 1.1 de la CADH también contiene la expresión "otra condición social” a los efectos de bloquear actos de discriminación. En igual suerte que el texto de la $\mathrm{CADH}$, esta nomenclatura ha sido interpretada en el sentido de incluir la categoría de orientación sexual.

Por consiguiente, el Comité de Derechos Humanos (1994, párr. 8.2-8.7) ha sostenido que la mención de una "protección igual y efectiva contra cualquier discriminación por motivos de raza, color, sexo, idioma, religión, opiniones políticas o de cualquier índole, origen nacional o social, posición económica, nacimiento o cualquier otra condición social” en el artículo 26 del PIDCP (NACIONES UNIDAS, 1966) incluye la discriminación por razones de orientación sexual. Por su parte, el Comité de Derechos Económicos, Sociales y Culturales (2000, párr. 18) ha dicho que:

en virtud de lo dispuesto en el párrafo 2 del artículo 2 y en el artículo 3 [del Pacto Internacional de Derechos Económicos, Sociales y Culturales], el Pacto prohíbe toda discriminación en lo referente al acceso a la atención de la salud y los factores determinantes básicos de la salud, así como a los medios y derechos para conseguirlo, por [...] el estado de salud (incluidos elVIH/SIDA), la orientación sexual [...], que tengan por objeto o por resultado la invalidación o el menoscabo de la igualdad de goce o el ejercicio del derecho a la salud.

Además, tal como surge del informe de la Comisión Internacional de Juristas (2009, p. 34), el Comité contra la Tortura (2008, párr. 21 y 22) ha entendido que la orientación sexual 
y la identidad transexual son una de las razones prohibidas incluidas en el principio de no discriminación. Asimismo, el Comité de los Derechos del Niño (2003b, párr. 6; 2003a, párr. 8) ha enumerado la orientación sexual entre las razones prohibidas de discriminación en sus Observaciones Generales relativas a la salud y el desarrollo de los adolescentes, el VIH/SIDA y los derechos del niño.

Ahora bien, como puede advertirse, la categoría de “orientación sexual” ha sido la primera en despertar preocupación en cuanto a su tutela por los órganos antedichos. Esto se debe a que la categoría de identidad de género se materializa en la sociedad de forma mucho más rupturista al momento de desafiar la inscripción corporal dentro de la dicotomía referida supra acerca del binomio naturaleza/cultura. No obstante, este ciclo de interpretación evolutiva debe reconocer como punto de cierre la postura de la Corte IDH ya citada, en la cual se menciona de manera expresa la inclusión de la categoría de identidad de género como elemento prohibitivo de discriminación, a pesar de que el caso de fondo sometido a su competencia contenciosa solo estaba vinculado a un asunto de discriminación por orientación sexual. A nivel normativo, esto queda evidenciado a través de la expresa mención de lege lata de la identidad de género en la Convención Interamericana sobre la Protección de los Derechos Humanos de las Personas Mayores (CIPDPM) cuyo artículo 5 establece:

Los Estados Parte desarrollarán enfoques específicos en sus políticas, planes y legislaciones sobre envejecimiento y vejez, en relación con la persona mayor en condición de vulnerabilidad y aquellas que son víctimas de discriminación múltiple, incluidas las mujeres, las personas con discapacidad, las personas de diversas orientaciones sexuales e identidades de género... (ORGANIZACIÓN DE LOS ESTADOS AMERICANOS, 2015, el relieve me pertenece)

Este texto que fue aprobado el 15 de junio de 2015 en el seno de la Organización de los Estados Americanos pone en evidencia el reconocimiento convencional del derecho a la identidad de género coincidente con la evolución jurisprudencial antes referida a la que ya había llegado la Corte IDH. Aún más, esta redacción define el dinamismo intrínseco de la categoría en análisis ya que el uso del plural en el texto obedece a un paradigma de comprensión de los derechos de la comunidad LGBTI en términos de sexualidades e identidades diversas, imposible de ser catalogadas de antemano. Además, resulta alentador que este tipo de derechos se encuentre recogido en una convención internacional relativa a personas ancianas, ya que los datos de la realidad indican que el promedio de vida de las personas transexuales no supera los 30-35 años de edad ${ }^{\mathbf{1}}$. Esto quiere decir que son muy pocas las perso-

1 Dato referido a la región Latinoamericana. Véase el Informe sobre Violencia contra Personas LGBTI (COMISIÓN INTERAMERICANA DE DERECHOS HUMANOS, 2015, p. 16). 
nas transexuales que llegan a la edad normativamente estipulada para considerar a una persona como adulto mayor. Esto se debe a que:

se trata de personas que han padecido la estigmatización violenta de la "primera sociedad” que las mira, o sea, la propia familia. A esto se le suma la falta de escolarización como consecuencia de exclusión directa por prácticas discriminatorias o por autoexclusión.Y luego la imposibilidad de acceder al mercado laboral debido a la imagen contraria a los estereotipos socioculturales hegemónicos... Todo esto lleva a que el espacio en el que ellas encuentran una forma de subsistencia económica es aquél vinculado al ejercicio de la prostitución. (ARRUBIA, 2016, p. 29)

De esta manera, la escasez de recursos y el escenario vulnerable de la prostitución exponen a las personas trans a las enfermedades de trasmisión sexual, todo lo cual opera directamente como un factor de reducción de su expectativa y calidad de vida. Sin embargo, siguiendo a Roqué (2015, p. 73), debe afirmarse que debido a los avances de la medicina y las ciencias de la salud en general el aumento de la longevidad aparece como una de las grandes conquistas del siglo XX. Por eso la autora advierte que esto plantea el desafío de optimizar las mejores condiciones de autonomía, con el ejercicio pleno de todos los derechos humanos y libertades fundamentales de las personas mayores. Sin duda, dentro de estos desafíos se halla el respeto a los derechos vinculados a la orientación sexual e identidades de género en esta etapa de la vida, lo cual convierte al texto de la convención en un hito paradigmático.

No obstante, a pesar de esta consagración normativa convencional, advierto que el derecho a la identidad de género ya venía despertando preocupaciones en el ámbito internacional desde años anteriores a la CIPDPM. En este sentido, a modo ejemplificativo, se destacan las palabras del Relator Especial sobre la tortura y otros tratos o penas cueles, inhumanos o degradantes, quien sostuvo:

[L]os miembros de las minorías sexuales se les somete en una proporción excesiva a torturas y otros malos tratos porque no responden a lo que socialmente se espera de uno y otro sexo. De hecho, la discriminación por razones de orientación o identidad sexuales puede contribuir muchas veces a deshumanizar a la víctima, lo que con frecuencia es una condición necesaria para que tengan lugar la tortura y los malos tratos. (NACIONES UNIDAS, 2001, p. 6, párr. 19)

Por otro lado, más allá de la protección en contra de la discriminación por razones de identidad de género, corresponde atender a los despliegues del derecho a la identidad de género per se. En este sentido, la intimidad y dignidad de la persona humana exigen que las personas trans sean removidas de la esfera de la medicalización y la patología para reubicarlas en un espacio identitario propio e igualmente válido (SIVERINO BAVIO, 2016, p. 174). Esto 
significa que la decisión de optar o no por una intervención quirúrgica de reasignación sexual constituye una conducta autorreferente tutelada por el derecho a la intimidad y, en consecuencia, la exigencia de modificar el asiento registral deriva del derecho a la identidad, el reconocimiento de la personalidad jurídica y la autonomía (SIVERINO BAVIO, 2016, p. 176). Asimismo, en relación a la tutela de la vida privada de las personas por parte de la CIDH se ha sostenido que:

... la vida privada incluye además el respeto al libre desarrollo de la personalidad, es decir, la tutela del derecho a la autodeterminación de los aspectos esenciales que construyen la identidad del individuo, como por ejemplo, su sexualidad. Así, la vida privada, y por ende, el artículo 11.2 de la Convención Americana, garantizarían también que los individuos tengan la posibilidad de establecer relaciones públicas respecto de tales autodeterminaciones, las mismas que no pueden -ni deben-quedar confinadas al espacio o esfera íntima. La consecuencia práctica de esta nueva dimensión obliga a rechazar no sólo las normas que penalizan o patologizan la sexualidad diversa - por ejemplo, la conducta homosexual o la transgeneridad - sino que además garantiza el respeto de las expresiones públicas de afecto de las personas al margen de su orientación sexual e identidad de género. (BERTONI; ZELADA, 2014, p. 283)

En este orden de ideas, resulta interesante traer a colación la evolución de la jurisprudencia del Tribunal Europeo de Derechos Humanos (TEDH), a través de la cual se ilustra la conformación del derecho a la identidad de género. De este modo, el sistema europeo claramente adopta la comprensión binaria de los sexos al sostener en el artículo 12 del Convenio Europeo de Derecho Humanos (CEDH) que “...el hombre y la mujer tienen derecho a casarse y a fundar una familia según las leyes nacionales que rijan el ejercicio de este derecho" (TRIBUNAL EUROPEO DE DERECHOS HUMANOS, 1950). De esta manera, el mensaje legal implica que se es hombre o se es mujer, no otra cosa, dejando así afuera otras manifestaciones de la sexualidad como los casos de personas intersex o hermafroditas (GONZALEZ-ZALZBERG, 2014, p. 803). La pregunta evidente que emerge ante este panorama convencional binario es aquella vinculada a la personalidad de los sujetos transgéneros y sus consiguientes derechos. Así, en una primera etapa a partir de $1986^{2}$ el TEDH respaldó la comprensión binaria de los sexos que emergía de la normativa convencional antes citada (DUTERTRE, 2003, p. 350) y así entendió que si bien existía un derecho a la identidad que permitía a la persona asumir una vida conforme al género sentido, se denegaba el ejercicio de otros derechos tales como la

2 Véase Tribunal Europeo de Derechos Humanos. Rees vs. United Kingdom (1986), Cossey vs. United Kingdom (1990) y Sheffield and Horsham vs. United Kingdom (1998). 
rectificación de la partida de nacimiento, el matrimonio de acuerdo al nuevo género, el derecho a pensión, etc. Para ello, el tribunal de Estrasburgo invocaba la existencia de un amplio margen de apreciación de los Estados para regular este tipo de cuestiones que dependían de parámetros socioculturales propios de cada país (ARAI-TAKAHASHI, 2001, p. 71). Al menos, se dejó asentado en la sentencia del caso Cossey en 1990 que sus decisiones no eran definitivas, dado que este tipo de asunto requería una interpretación evolutiva que podía hacer que en el futuro, producto del desarrollo de las sociedades, pudiera reconocerse la plenitud de los efectos jurídicos al cambio de género (DOTHAN, 2015, p. 229). No obstante, estos primeros pronunciamientos del TEDH resultaron paradójicos ya que se aseveraba que el verdadero sexo era el biológico de nacimiento, incluso a pesar de que luego la persona lo hubiera modificado quirúrgicamente, pero aun así se generaba que la persona fuera considerada hombre para algunos asuntos y mujer para otros (GONZALEZ-ZALZBERG, 2014, p. 809).

Ahora bien, en el año 2002 el Tribunal dio el giro esperado en los famosos casos "Goodwin" e "I.", ambos contra el Reino Unido. A partir de aquí, se abandonó la doctrina anterior la cual implicó que el derecho a la identidad de género se reconociera incluso hasta permitir la modificación registral de las partidas de nacimiento con el consecuente goce de los derechos inherentes al nuevo género asumido. Se puso el énfasis argumentativo en la tutela de la autonomía de la persona la cual siempre debe prevalecer ante una situación relativa a la vida privada como lo es el diseño de los datos personales que hacen a la propia identidad (HERALD, 2009, p. 194). El TEDH entendió que el nuevo escenario social europeo mostraba mayor tolerancia hacia los derechos de las personas trans, por lo cual ya no se justificaba seguir incluyendo este tipo de asunto dentro del margen de apreciación de los Estados y, por consiguiente, se catalogó el accionar de las autoridades públicas británicas como una injerencia estatal ilegítima lesiva del derecho a la vida privada y familiar protegido por el artículo 8 del CEDH (BJORGE, 2015, p. 181). Sin embargo, para los jueces no alcanzaba con que la persona se asumiera como transgénero sino que debía ser transexual, esto es, haber modificado quirúrgicamente su sexo porque se sostenía una creencia según la cual el género debía ser determinado por el sexo biológico. Entonces para asumir un género diferente del correspondiente al sexo asignado al nacer se requería que éste fuera reconstruido (GONZALEZ-ZALZBERG, 2014, p. 811).

Finalmente, la última sentencia que se registra en el sistema regional europeo de Derechos Humanos relacionada al derecho a la identidad de género es la del caso "Y.Y. vs. Turquía”. En esta causa, se trató de una persona de sexo biológico femenino la cual el Estado le denegaba la posibilidad de acceder a una cirugía de reasignación de su sexo a los efectos de poder asumir un cuerpo masculino conforme a su género autopercibido. El argumento de las autoridades de Turquía se basaba en el hecho de que la persona podía conservar sus funciones biológicas de procreación a pesar de atravesar el procedimiento quirúrgico, mientras que el artículo 40 del Código Civil turco exigía que para acceder a esta operación el individuo debía ser 
permanentemente infértil (WICKS, 2016, p. 123). Luego de un tiempo considerable el Estado permitió que esta reasignación se llevara a cabo. El TEDH determinó la responsabilidad internacional de Turquía considerando que durante todo ese tiempo de negativa se había producido una injerencia estatal ilegítima en derechos personalísimos como lo son el de la identidad de género y la disposición del propio cuerpo.

\section{Cláusulas convencionales de igualdad en Relación CON El DeRecho A} LA IDENTIDAD DE GÉNERO: DESDE LA NORMA INTERNACIONAL HACIA LA SITUACIÓN CONCRETA DE COSTA RiCA

En relación a las cláusulas de igualdad de la CADH transcriptas supra, Uprimny y Sanchez (2014, p. 583) advierten que la cláusula del artículo 1.1 es subordinada, mientras que la del artículo 24 es autónoma. Esto quiere decir que en la que es subordinada se consagra la igualdad como garantía accesoria a otro derecho o libertad, mientras que la que es autónoma contiene una prohibición de discriminación genérica en la aplicación de las leyes de los estados parte. El artículo 1.1 se restringe a todos los derechos consagrados en la CADH, pero el 24 va más allá y extiende la prohibición de discriminación a las normas internas de los Estados (UPRIMNY; SANCHEZ, 2014, p. 584). Por lo tanto, del hecho intrínseco de que el artículo 24 mencionado sea una cláusula autónoma, se desprenderán las siguientes características: 1) consagra un derecho independiente de los demás derechos; 2) genera derechos y deberes específicos de protección para los Estados, en tanto que es un derecho autónomo; 3) se refiere específicamente a la garantía de igualdad frente a las disposiciones de derecho interno de los estados y las actuaciones de sus autoridades (UPRIMNY; SANCHEZ, 2014, p. 585).

En esta línea, la CIDH a la hora de interpretar el artículo 24 antes mencionado, en el caso Morales de Sierra, entendió que existe un principio según el cual ciertas formas de diferencia en el trato devienen fuertemente sospechosas de ilegalidad y, por consiguiente, el Estado debe alegar razones suficientemente justificantes para mantenerlas (ABRAMOVICH, 2006, p. 44). Siempre que estas distinciones se apoyen en un factor susceptible de generar "sospecha" de discriminación negativa tales como la raza, la religión, el sexo, etc. será necesario que la norma o política que los utiliza sea revisada a través de un escrutinio estricto. Como consecuencia de este informe de la Comisión, el Estado de Guatemala se vio obligado a modificar su legislación interna que confería la administración exclusiva de la sociedad conyugal al esposo varón (ABRAMOVICH, 2006, p. 44).

De esta manera, en analogía con lo sucedido respecto del Código Civil de Guatemala, el artículo 54 del Código Civil de Costa Rica configura una disposición discriminatoria que transgrede el artículo 24 de la CADH. Es decir, si bien es evidente que el requisito de trámite judicial a los efectos de la modificación del nombre de una persona humana es prima facie compatible con el artículo 18 de esta Convención, que sujeta el derecho al nombre a la reglamentación que cada Estado haga mediante un dispositivo legal interno, lo cierto es que 
en materia de casos vinculados al pleno ejercicio del derecho a la identidad de género, dicha reglamentación emanada del ordenamiento doméstico del Estado costarricense deviene irrazonable. Resulta que la regulación que de alguna manera restrinja un derecho, además de cumplir con requisitos de forma, debe observar cuestiones sustanciales que atañen al contenido de ese derecho mismo (DULITZKY, 2006, p. 103). Así ha quedado establecido por la Corte IDH (1985, párr. 37) al pronunciarse en la opinión consultiva acerca de la colegiación obligatoria de periodistas. Es decir, las restricciones deben fijarse de conformidad con ciertos requisitos formales vinculados a los medios a través de los que se manifiestan, pero además, deben atender a condiciones de fondo que son representadas por la legitimidad de los fines que se pretendan lograr con dichas restricciones (PINTO, 2008, p. 102). En este orden, esta irrazonabilidad se funda en que, a la luz de lo dispuesto por el artículo 1.1 de la CADH interpretado conforme la jurisprudencia de la Corte IDH como se explicara previamente, la judicialización de la intimidad de la persona que asume una identidad de género diferente de la que se le ha atribuido culturalmente representa una intromisión o injerencia estatal ilegítima. Así, queda lesionado también el artículo 11 de la Convención en análisis. Con más precisión, esta transgresión normativa aparece evidenciada si tomamos como referencia el documento de la propia Comisión Interamericana de Derechos Humanos (2012, párr. 31) en el que se alegó que las categorías de derechos vinculadas a la diversidad sexual, entre ellas la identidad de género, componen el contenido sustancial del derecho a la vida privada de la persona.

Adicionalmente, a modo de guía interpretativa resulta enriquecedor traer a colación el texto del apartado D del tercer principio de Yogyakarta en relación al reconocimiento de la personalidad jurídica y en virtud del cambio de nombre vinculado al ejercicio del derecho a la identidad de género. Este principio alude a que los Estados "garantizarán que tales procedimientos sean eficientes, justos y no discriminatorios y que respeten la dignidad y privacidad de la persona concernida" (COMISIÓN INTERNACIONAL DE JURISTAS, 2007, p. 12). Desde esta óptica se puede advertir que un trámite judicial para lograr el cambio de nombre en personas transexuales, travestis o transgénero es lesivo de la intimidad de la persona que queda expuesta al contralor de un magistrado. Sobre todo si se repara en que éste, en ocasión del ejercicio de prerrogativas que cada legislación procesal interna le otorgue, podrá agravar la situación de discriminación social a la que el o la justiciable está sometida/o exigiendo comparecencias, audiencias, peritajes, etc. por demás innecesarios ya que cada persona tiene el derecho fundamental de autodeterminar su propia identidad de género siendo el nombre una manifestación elemental de esa autonomía. En cambio, el trámite administrativo permite que la persona pueda solicitar la modificación y sustitución del nombre registral por otro que se corresponda con su identidad de género. Ante esta petición, la autoridad administrativa se ve constreñida a conceder dicha solicitud sin posibilidad de exigir ningún tipo de prueba al respecto. Es decir, el hecho de la petición de la persona es por sí mismo probatorio de su identidad de género ya que el carácter profundamente íntimo de esta noción se basa única y suficientemente en la autopercepción del género. En contraposición, cuando una petición de esta 
naturaleza es sometida al escrutinio de un juez el trámite puede prolongarse en el tiempo lesionando el derecho de la persona y simultáneamente habilita al juzgador a requerir medidas probatorias sobre un aspecto íntimo de la vida humana como lo es la identidad de género. Además, debe tenerse en cuenta las costas económicas que genera un proceso judicial sumando los gastos de honorarios profesionales del abogado representante de quien desea cambiar su nombre. En consecuencia, el trámite administrativo con las características mencionadas debe regularse a través de una ley del Estado que asegure la protección plena de este derecho en los términos aquí planteados.

En este sentido, la experiencia de Argentina resulta esclarecedora en la materia ya que este Estado sancionó en el año 2012 la Ley de Identidad de Género n. 26.743 que define a este derecho de la misma manera en que lo había hecho de la CIDH conforme quedó dicho al comienzo de este trabajo. Así, se produce un proceso de desjudicialización y de despatologización, lo cual implica que la persona pueda peticionar el cambio de nombre conforme con su identidad de género autopercibida ante el Registro de las Personas, o sea, una sede administrativa (artículo 3). Para ello, no se necesita acreditar la existencia de una intervención quirúrgica por reasignación genital total o parcial, ni acreditar terapias hormonales u otro tratamiento psicológico o médico (artículo 4). Esto significa que "para las instituciones del Estado, la genitalidad deja de ser el destino del cuerpo que lo porta. En efecto, la ley desactiva los determinismos psicológicos y el naturalismo corporal e identitario, que sirvió como fundamento para colonizar las corporalidades diversas" (LITARDO, 2013, p. 251).

En relación a lo que sucede en Costa Rica, dentro del marco normativo anteriormente descripto, en el año 2014 se dio un caso ante el juzgado civil de mayor cuantía de Heredia. En esta oportunidad, una persona de sexo biológico masculino inició una acción judicial con la finalidad de obtener la modificación de su nombre registral. Ante esta petición, el juez denegó el cambio solicitado ya que el nuevo nombre alegado era "Kala” y la terminación del mismo con la letra "a” representaba al sexo femenino contrario a la identidad del accionante. Por lo tanto, la persona afectada apeló la sentencia ante el Tribunal Civil de Heredia, el cual dictó su pronunciamiento revocando la sentencia de primera instancia y ordenando que se asentara el cambio de nombre solicitado en el Registro correspondiente. Así, el Tribunal fundamenta su decisión en el derecho al cambio de nombre y el derecho a la intimidad, pero al mismo tiempo sostiene que en el caso no aparece involucrado el género de la persona. Para ello sostiene que "el promovente en el ámbito de su familia y de sus amigos, es identificado como 'Kala' sin que ello afecte su identidad, su intimidad, ni su género" (TRIBUNAL DE HEREDIA, 2014, párr. 2). Por lo tanto, puede advertirse que el Tribunal no se manifestó en relación a las consecuencias de asumir una identidad de género culturalmente diversa, ni a la importancia de que la misma sea reconocida a través del nombre libremente escogido por la persona en sede administrativa.

Adicionalmente, el Estado de Costa Rica a través del Tribunal Supremo de Elecciones modificó en el año 2016 el Reglamento de Fotografías para la Cédula de Identidad que había 
sido promulgado en el año 2010. Esta norma tiene la finalidad de regular la recepción y aprobación de las imágenes contenidas en el documento de identificación individual de los ciudadanos costarricenses. En este sentido, se dispone que toda persona tiene el derecho a que se respete su imagen e identidad de género al momento de tomarse la fotografía que se inserta en la cédula de identidad (artículo 2). De este modo, el reglamento se refiere al concepto de sexo registral como aquel declarado por las personas progenitoras o por la autoridad competente en la declaración de un nacimiento y que consta en el Registro Civil (artículo 3). Y también define a la identidad de género como "la vivencia interna e individual del género, que no necesariamente corresponde con el sexo asignado al momento del nacimiento. Alude a la autopercepción y al cómo se asume la persona en su identidad, funciones y atributos" (TRIBUNAL SUPREMO DE ELECCIONES, 2016, artículo 3). Al mismo tiempo, el reglamento impone a los funcionarios públicos el deber de velar “...porque cada gestión se resuelva en el marco de una filosofía de pleno respeto al derecho a la imagen y a la identidad de género de la persona usuaria...” (TRIBUNAL SUPREMO DE ELECCIONES, 2016, artículo 4).

Sin embargo, corresponde señalar que a pesar de estos avances el cambio de nombre de forma congruente con la identidad de género real de la persona encuentra un gran obstáculo en el artículo 54 del Código Civil de Costa Rica al que se ha hecho referencia supra. De manera tal que actualmente solo es posible acceder a dicha modificación completa por medio de un proceso judicial. En este contexto, debe destacarse a título de buenas prácticas el reconocimiento que se dispensa a las personas trans en algunas entidades. Por ejemplo, el 7 de marzo de 2017 el rector de la Universidad de Costa Rica, Henning Jensen, dictó una resolución oficial por medio de la cual se reconoció el derecho de los estudiantes trans a que sean nombrados en los documentos universitarios de acuerdo con el nombre que satisfaga su verdadera identidad de género ${ }^{3}$.

\section{CONCLUSIÓN}

En suma, se han explorado y fundamentado los desarrollos del derecho a la identidad de género en el seno del Derecho Internacional de los Derechos Humanos. Para ello se analizaron los despliegues de este derecho vinculados a la discriminación negativa, por un lado, y a su fundamentación intrínseca a través de la intimidad y la vida privada, por el otro. El concepto mismo de género pone en evidencia la construcción social de la existencia de hombres y mujeres. El derecho en general y el Derecho Internacional de los Derechos Humanos no han sido ajenos a este reconocimiento. De esta manera, la apelación al principio de interpretación pro persona ha

3 Véase: <https://www.laprensalibre.cr/Noticias/detalle/61822/ucr-reconoce-derecho-al-nombre-aestudiantes-trans >. Acceso el: 31 dic. 2017. 
permitido valorar la dignidad humana a los efectos de dar legitimidad dentro del campo operativo de los derechos humanos al derecho a la identidad de género.

Por consiguiente, se concluye que el artículo 54 del Código Civil de Costa Rica es incompatible con los artículos 11, 18 y 24 en relación con el artículo 1.1 de la Convención Americana de Derechos Humanos, siempre que se trate de la modificación del nombre de una persona humana con motivo del ejercicio de su derecho a la identidad de género. Se advierte que el trámite más congruente con el respeto a este derecho y, por tanto, no discriminatorio, es aquel que se establece en sede administrativa registral no judicial, siempre que a su vez permita el acceso rápido, eficaz y sin dilaciones por parte de la persona directamente interesada conforme a la propia autopercepción de su género, al sentir y a la vivencia de su sexualidad y corporalidad de las cuales solo dicha persona puede ser artífice con exclusión de terceros, sean particulares o sea el Estado. El análisis de la situación fáctica y legal de Costa Rica ha permitido advertir cómo se produce la vulneración del derecho a la identidad de género a la luz de los estándares internacionales en materia de derechos humanos y diversidad sexual.

\section{REFERENCIAS}

ABRAMOVICH, Victor. Una aproximación al enfoque de derechos en las estrategias y políticas de desarrollo. Revista de la CEPAL, n. 88, p. 35-50, 2006.

ARAI-TAKAHASHI, Yutaka. The margin of appreciation doctrine and the principle of proportionality in the jurisprudence of the ECHR. New York: Intersentia, 2001.

ARRUBIA, Eduardo. ¿Iguales o diferentes? Los derechos de las personas LGBTI en discusión. Revista de la Facultad de Derecho, n. 41, p. 15-34, 2016. Disponible en: <http://revista.fder.edu.uy/index.php/rfd/ article/view/554>. Acceso el: 20 marzo 2018.

BERLIN, Isaiah. Liberty. Incorporating four essays on liberty. New York: Oxford University Press, 2002.

BELOFF, Mary. El derecho de los niños a su protección especial en el Sistema Interamericano. Buenos Aires, 2016. En preparación.

BERTONI, Eduardo; ZELADA, Carlos. Protección de la honra y de la dignidad. En STEINER, Christian; URIBE Patricia (Ed.). Convención Americana de Derechos Humanos - Comentario. Berlín: Konrad Adenauer Stiftung, 2014. Impreso en Bolivia por Plural editores en junio de 2014. 
BJORGE, Eirik. Domestic application of the ECHR. Courts as faithful trustees, New York: Oxford University Press, 2015.

COMISIÓN INTERAMERICANA DE DERECHOS HUMANOS. Convención Americana sobre Derechos Humanos (Suscrita en San José de Costa Rica el 22 de noviembre de 1969, en la Conferencia Especializada Interamericana sobre Derechos Humanos). San José, 1969. Disponible en: <https: / /www.cidh.oas.org/ Basicos/Spanish/Basicos2.htm>. Acceso el: 20 marzo 2018.

- Orientación sexual, identidad de género y expresión de género: algunos términos y estándares relevantes. 2012. Disponible en: <http: / /scm.oas.org/pdfs/2012/CP28504S.pdf>. Acceso en: 20 marzo 2018. . Violencia contra personas lesbianas, gays, bisexuales, trans e intersex en América. 2015. Disponible en: <http://www.oas.org/es/cidh/informes/pdfs/violenciapersonaslgbti.pdf>. Acceso el: 20 marzo 2018.

COMISIÓN INTERNACIONAL DE JURISTAS. Identidad de género y Derecho Internacional de los Derechos Humanos. Guía para profesionales n. 4. Ginebra, 2009. Disponible en: <http://pfdc.pgr.mpf.mp.br/ atuacao-e-conteudos-de-apoio/publicacoes/direitos-sexuais-e-reprodutivos/direitos-lgbtt/orientacionsexual- e-identidad-de-genero-y-derecho-internacional-de-los-derechos-humanos $>$. Acceso el: 20 marzo 2018.

Principios deYogyakarta - Principios sobre la aplicación de la legislación internacional de derechos humanos en relación con la orientación sexual y la identidad de género. Marzo de 2007. Disponible en: $<$ http: / /www.refworld.org/cgi-bin/texis/vtx/rwmain/opendocpdf.pdf?reldoc=y\&docid=48244e9f2 >. Acceso el: 20 marzo 2018.

COMITÉ CONTRA LA TORTURA. Observación General n. 2: Aplicación del Artículo 2 por los Estados Parte. 24 de enero de 2008.

COMITÉ DE DERECHOS ECONÓMICOS, SOCIALESY CULTURALES. Observación General n. 14 : El derecho al disfrute del más alto nivel posible de salud (Artículo 12). 11 de agosto de 2000.

COMITÉ DE DERECHOS HUMANOS. Nicholas Toonen v. Australia. Comunicación n. 488/1992, U.N. Doc. CCPR/C/50/D/488/1992, 1994.

COMITÉ DE LOS DERECHOS DEL NIÑO. Observación General n. 3. VIH/SIDA y los derechos del niño. Marzo de 2003a.

Observación General n. 4. Salud y Desarrollo de los Adolescentes. Julio de 2003b. 
CORTE IDH. Caso 19 Comerciantes contra Colombia. Sentencia de Fondo y Reparaciones. 5 de julio de 2004. . Atala Riffo y niñas contra Chile. Sentencia Fondo, Reparaciones y Costas. 24 de febrero de 2012. Flor Freire contra Ecuador. Sentencia Fondo, Reparaciones y Costas. 31 de agosto de 2016. La colegiación obligatoria de periodistas (artículos 13 y 29 Convención Americana sobre Derechos Humanos). Opinión Consultiva OC-5/85 de 13 de noviembre de 1985.

Identidad de género, e igualdad y no discriminación a parejas del mismo sexo - Obligaciones estatales en relación con el cambio de nombre, la identidad de género, y los derechos derivados de un vínculo entre parejas del mismo sexo (interpretación y alcance de los artículos 1.1, 3, 7, 11.2, 13, 17, 18 y 24, en relación con el artículo 1 de la Convención Americana sobre Derechos Humanos). Opinión Consultiva OC-24/17 de 24 de noviembre de 2017.

COSTA RICA. Ley n. 63 de 28 de setiembre de 1887 (Código Civil). San José, 1887. Disponible en: <http: / / www.pgrweb.go.cr/scij/Busqueda/Normativa/Normas/nrm_texto_completo.aspx? nValor1=1\&nValor2=15437>. Acceso el: 20 marzo 2018.

DOTHAN, Shai. Reputation and judicial tactics. A theory of national and international courts. New York: Cambridge University Press, 2015.

DULITZKY, Ariel. Alcance de las obligaciones internacionales de los Derechos Humanos. En: MARTIN, Claudia; RODRIGUEZ-PINZÓN, Diego; GUEVARA, José (Comps.). Derecho Internacional de los Derechos Humanos. México D.F.: Universidad Iberoamericana, A. C., 2006.

DUQUE YEPES, Hernando. La excelencia como ideal y realidad en el ser humano. Bogotá: Editorial San Pablo, 2006.

DUTERTRE, Gilles. Key case - Law extracts. European court of human rights. Strasbourg: Council of Europe Publishing, 2003.

FERNANDEZ SESSAREGO, Carlos. Derecho a la identidad personal. Buenos Aires: Astrea, 1992.

GOFFMAN, Irving. Estigma. La identidad deteriorada. Buenos Aires: Amorrortu, 2012.

GONZALEZ-ZALZBERG, Damian. The accepted transsexual and the absent transgender: a queer reading of the regulation of sex/gender by the European Court of Human Rights. The American University International Law Review, v. 29, n. 4, p. 797-829, 2014. 
HERALD, Marybeth. Explaining the differences: Transgender theories and court practice. En: BARCLAY, Scott; BERNSTEIN, Mary; MARSHALL, Anne-Marie (Eds.). Queer movilizations. New York: New York University Press, 2009.

LAMAS, Marta. Cuerpo: Diferencia sexual y género. México D.F.: Ed. Taurus-Pensamiento, 2002.

LITARDO, Emiliano. Los cuerpos desde ese otro lado: la ley de identidad de género en Argentina. Meritum. v. 8, n. 2, p. 227-255, 2013.

NACIONES UNIDAS - Oficina del Alto Comisionado de las Naciones Unidas para los Derechos Humanos (OACDH). Informe del Relator Especial sobre la cuestión de la tortura y otros tratos o penas crueles, inhumanos o degradantes. Informe provisional A/56/156 de 3 de julio de 2001.

. Pacto Internacional de Derechos Civiles y Políticos. Adoptado y abierto a la firma, ratificación y adhesión por la Asamblea General en su resolución 2200 A (XXI), de 16 de diciembre de 1966.

NINO, Carlos. Ética y derechos humanos. Buenos Aires: Astrea, 2007.

ORGANIZACIÓN DE LOS ESTADOS AMERICANOS. Convención Interamericana sobre la Protección de los Derechos Humanos de las Personas Mayores. Washington, D.C., 2015. Disponible en: <http:// www.oas.org/es/sla/ddi/tratados_multilaterales_interamericanos_A-70_derechos_humanos_personas_ mayores.asp>. Acceso en: 20 marzo 2018.

PINTO, Mónica. El derecho internacional. Vigencia y desafíos en un escenario globalizado. Buenos Aires: Fondo de Cultura Económica, 2008.

PRIETO SANCHIS, Luis. Tolerancia y minorías: Problemas jurídicos y políticos. La Mancha: Servicio de Publicaciones de la Universidad Castilla, 1996.

REY CANTOR, Ernesto. Celebración y jerarquía de los Tratados de Derechos Humanos (Colombia y Venezuela). Caracas: Universidad Católica Andrés Bello, 2007.

ROQUÉ, Mónica. El camino de la comunidad internacional. En: DABOVE, María Isolina (Dir.). Derechos Humanos de las personas mayores. Acceso a la justicia y protección internacional. Buenos Aires: Astrea, 2015.

RUIZ, Alicia. La imagen que nos devuelve el derecho. En: FAUR, Eleonor; LAMAS, Alicia (Comps.). Derechos universales, realidades particulares. Reflexiones y herramientas para la concreción de los derechos humanos de mujeres, niños y niñas. UNICEF, 2003. 
SIVERINO BAVIO, Paula. El derecho a la identidad: La ley de identidad de género y sus proyecciones. Revista de Derecho Privado y Comunitario. Santa Fe: Rubinzal-Culzoni, 2015.

TRIBUNAL DE HEREDIA. Voto 100-02- 14. Costa Rica, 2014.

TRIBUNAL EUROPEO DE DERECHOS HUMANOS. Convenio Europeo de Derechos Humanos. 1950. Disponible en: <https://www.echr.coe.int/Documents/Convention_SPA.pdf>. Acceso el: 20 marzo 2018.

TRIBUNAL SUPREMO DE ELECCIONES. Decreto 03-2016. La Gaceta, n. 95, 18 de mayo del 2016. Disponible en: <https://www.imprentanacional.go.cr/pub/2016/05/18/COMP_18_05_2016.pdf>. Acceso el: 20 marzo 2018.

UPRIMNY, Rodrigo; SANCHEZ, Lus María. Igualdad ante la ley. En: STEINER, Christian; URIBE, Patricia (Ed.). Convención Americana de Derechos Humanos - Comentario. Berlín: Konrad Adenauer Stiftung, 2014. Impreso en Bolivia por Plural editores en junio de 2014.

WICKS, Elisabeth. The state and the body. Legal regulation of bodily autonomy. Oregon: Hart Publishing, 2016.

Eduardo J. Arrubia

Abogado. Becario de investigación doctoral del Consejo NaCiOnal de InVESTIGACIONES CIENTífICAS Y TÉCNICAS DE LA República Argentina (Conicet). Profesor Adjunto en la CÁtedra de Filosofía del Derecho y Ética de la Abogacía (Facultad de Derecho, Universidad Nacional del Centro de la Provincia de Buenos Aires). Doctorando en Derecho (UBA). Miembro del Centro de Estudios en Derechos HuMANOS (CEDH-UNICEN). earrubialamail.com 